\title{
Distribution characteristics of soil heavy metals in farmland soil around the mine area
}

\author{
Yinghao $\mathrm{Wu}^{1, \mathrm{a}}$, Jingying Chen ${ }^{1, \mathrm{~b}^{*}}$ and Bai $\mathrm{Gao}^{2, \mathrm{c}}$ \\ ${ }^{1}$ State Key Laboratory Breeding Base of Nuclear Resources and Environment, East China Institute \\ of Technology, Nanchang, 330013, Jiangxi, China \\ ${ }^{2}$ School of Water Resources \& Environmental Engineering, East China University of Technology, \\ Nanchang 330013, China

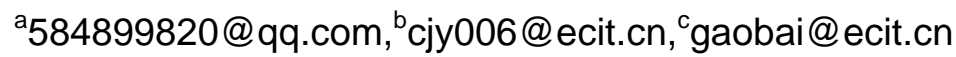

Keywords: Farmland soil around the mine area; Heavy metals; Distribution characteristics

\begin{abstract}
The acid waste water produced in the process of mine exploitation has greatly increased the migration and transformation of heavy metals, through the waste water and rainwater flow to the soil, did great harm to the use of the soil. Farmland soil around the mine area was studied in this paper, by using serpentine distribution method, after the samples have a certain amount of pretreatment, determination of heavy metals in soil by using X-ray fluorescence spectrometry to find distribution characteristics of heavy metals. The results show that the mean values of $\mathrm{Cr} 、 \mathrm{Mn}$ 、 $\mathrm{Ni} 、 \mathrm{Cu} 、 \mathrm{Zn}$ and $\mathrm{Pb}$ were greater than the national soil background values, also greater than the soil background values in Jiangxi. And besides Mn, The rest of the five elements in each sample point are more than national background value and background value of Jiangxi, But $\mathrm{Mn}$ in some of the sample points are also seriously overweight, the maximum value of $2813.220 \mathrm{mg} / \mathrm{kg}$ is up to around 11 times when compared with the soil background values in Jiangxi. With depth increasing, the content of $\mathrm{Cr}$ increased obviously, the content of $\mathrm{Pb}$ decreased significantly, the content of Mn has large fluctuations, $\mathrm{Ni}, \mathrm{Cu}$ and $\mathrm{Zn}$ are relatively stable.
\end{abstract}

\section{Introduction}

A large amount of acid waste water and waste slag produced during the mining process, the poisonous and harmful heavy metals will be on the emission of the acidic mining waste water and tailing heap of weathered and leached into the water environment, at the same time, heavy metals will also enter the soil, through the dissolution, precipitation, condensation, adsorptive complex and other series of reactions, form different chemical speciation and show different activity ${ }^{[1-2]}$.

Soil is the foundation of agricultural production, but also an indispensable part of human existence. Its quality directly affects people's production and life, With the increasing of population and resources demand, land use is limited, in the surrounding area of farmland, due to the exploitation of mines produce a large number of tailings sand and the wastewater produced by smelting process has serious harm on the soil. In particular, a large number of heavy metals through a series of migration and transformation into the soil, makes the use of soil limited, Such as $\mathrm{Pb}, \mathrm{Cu}$, $\mathrm{Zn}, \mathrm{Ni}$ accumulated too much will lead to the decline of soil microbial biomass, It has the inhibition effect on the growth of crops, and the pollution of heavy metals in the soil has the characteristics of concealment and long-term ${ }^{[3]}$. Therefore, The study of heavy metals in soil has important significance, it can provide a basis for the research of heavy metal pollution in mine soil.

\section{Experimental}

\section{Sample Collection.}

Farmland soil around the mine area was studied in this paper, because the study area isn't flat, the area is large, so use serpentine distribution method. Collect eight sections of soil samples, number 1, 3, 4, 5, 6, 7, 8, and 13 respectively. Dig a $1 \mathrm{~m}$ x $1.5 \mathrm{~m}$ rectangular hole in each of sections. Excavating the soil sections to make the observation surface face the sun. In each section 20, 40, 60, 
and $80 \mathrm{~cm}$ depths of the soil samples are collected. All point are located in the downstream of the tailings reservoir within 1000m of the Farmland soil.

\section{Sample pretreatment and analysis.}

The soil sample places in the laboratory oven for drying. Set the oven temperature to $70{ }^{\circ} \mathrm{C}$, drying time is $72 \mathrm{~h}$. After drying, grinding, and then put sample into the different size of the sieve to screen by GS-86 type electric shock screen machine. Sieved soil samples will put into sample bag to spare. According to the requirements of X-ray fluorescence spectrometry, heavy metals in soil samples will measure and analyze after 0.075 mm (200 mesh) screening.

\section{Results and discussion}

Content distribution characteristics of heavy metals.

According to the sample test results, the contents of heavy metals $\mathrm{Pb}, \mathrm{Mn}, \mathrm{Zn}, \mathrm{Ni}, \mathrm{Cu}$ and $\mathrm{Cr}$ in the soil of the sampling area were found in table 1.

Table 1 Total content of heavy metals in soil $\quad(\mathrm{mg} / \mathrm{kg})$

\begin{tabular}{ccccccc}
\hline & $\mathrm{Cr}$ & $\mathrm{Mn}$ & $\mathrm{Ni}$ & $\mathrm{Cu}$ & $\mathrm{Zn}$ & $\mathrm{Pb}$ \\
\hline Minimum & 122.615 & 156.947 & 37.930 & 41.638 & 120.807 & 36.293 \\
Maximum & 155.499 & 2813.220 & 63.290 & 91.561 & 178.892 & 65.873 \\
Average & 143.420 & 708.931 & 55.390 & 67.330 & 140.553 & 47.397 \\
Background value of Jiangxi $^{[4]}$ & 48.000 & 259.000 & 19.000 & 20.800 & 69.000 & 32.100 \\
Background value of national $^{[5]}$ & 61.000 & 583.000 & 26.900 & 22.600 & 74.200 & 26.000 \\
Quality standard value $^{[6]}$ & 250.000 & --- & 40.000 & 50.000 & 200.000 & 250.000 \\
\hline
\end{tabular}

From table 1, the mean values of $\mathrm{Cr} 、 \mathrm{Mn} 、 \mathrm{Ni} 、 \mathrm{Cu} 、 \mathrm{Zn}$ and $\mathrm{Pb}$ were greater than the national soil background values, also greater than the soil background values in Jiangxi. And besides Mn, The rest of the five elements in each sample point are more than national background value and background value of Jiangxi, But $\mathrm{Mn}$ in some of the sample points are also seriously overweight, the maximum value of $2813.220 \mathrm{mg} / \mathrm{kg}$ is up to around 11 times when compared with the soil background values in Jiangxi.

\section{Distribution characteristics of heavy metals in vertical.}

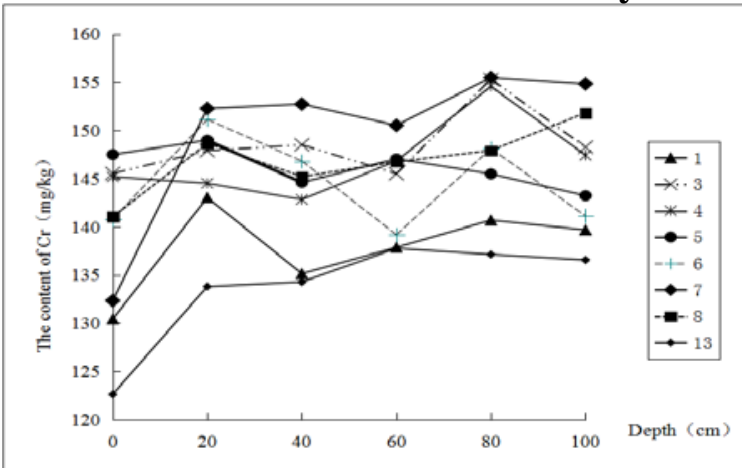

Fig. 1

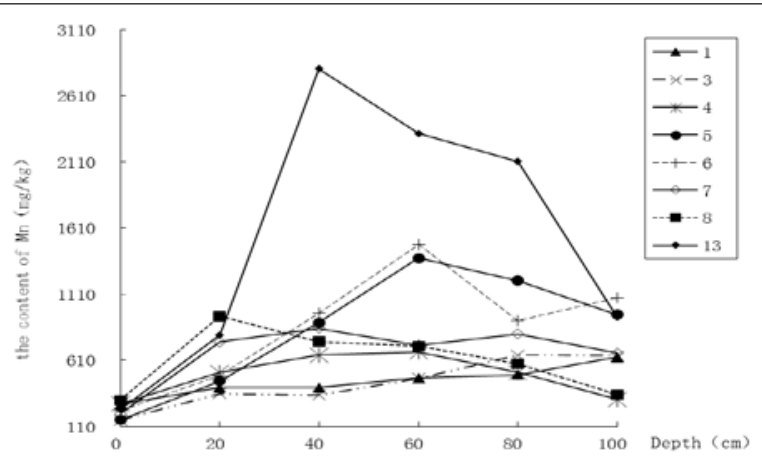

Fig. 2

(1) The vertical distribution characteristics of $\mathrm{Cr}$

Figure 1 shows the distribution of $\mathrm{Cr}$ in different depth of each section. The $\mathrm{Cr}$ increased with the increase of depth, and in different depth of each section is exceeded, reaching 2 times more than the background value of Jiangxi. At the same depth, the content of $\mathrm{Cr}$ in section 1 and section 13 was lower than that in other sections. Maybe due to the section 13 is far away from the tailings reservoir, and section 1 is located on the outside of the road, outside the road there has the drainage ditch, so the pollutant is difficult to be directly from the tailings reservoir into section 1 . Overall, $\mathrm{Cr}$ may be more prone to vertical migration.

(2) The vertical distribution characteristics of Mn

From Figure 2, with the increase of depth, the content of $\mathrm{Mn}$ in the soil has a slight upward trend in the vertical fluctuation. Section 5, section 6 and section 13 are all under the $200 \mathrm{mg} / \mathrm{kg}$ in 
the surface, but the $60 \mathrm{~cm}$ and $40 \mathrm{~cm}$ are above $1200 \mathrm{mg} / \mathrm{kg}$. In particular, the maximum value of the $\mathrm{Mn}$ is achieved above $2610 \mathrm{mg} / \mathrm{kg}$ in the depth of $40 \mathrm{~cm}$. But from the combination of sampling plan, section 5, section 6 and section 13, from the point of view, are relatively far from the tailings reservoir, The migration ability of $\mathrm{Mn}$ is good, but it is easy to accumulate in some local area, so it's possible to form the secondary pollution.

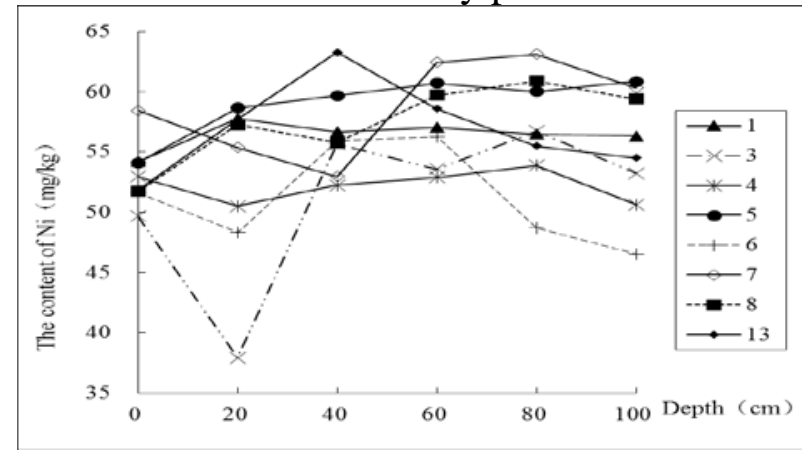

Fig.3

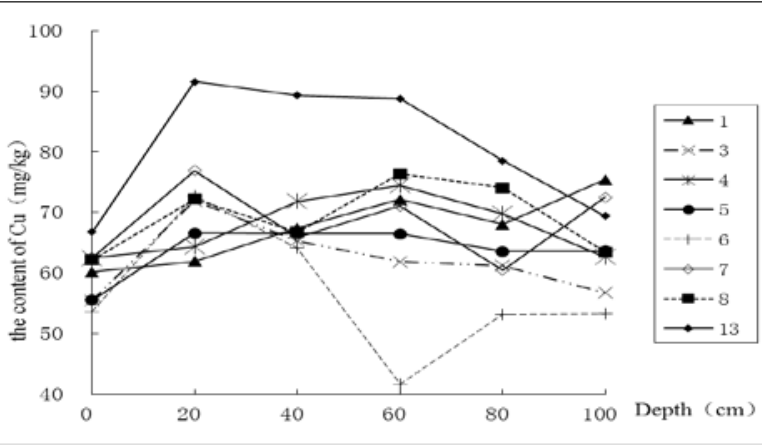

Fig. 4

(3) The vertical distribution characteristics of $\mathrm{Ni}$

From Figure 3, The content of $\mathrm{Ni}$ is roughly within a small range of $45-65 \mathrm{mg} / \mathrm{kg}$ in all sections, which seems to present a dynamic equilibrium phenomenon. This shows that the vertical distribution characteristics of $\mathrm{Ni}$ is uniform, and there is no obvious increase or decrease. But the content of $\mathrm{Ni}$ is minimal in the depth of the $20 \mathrm{~cm}$ of section 3 , and then with the increase of depth has rebounded.

(4) The vertical distribution characteristics of $\mathrm{Cu}$

From Figure 4, Except section 13 and section 6, the $\mathrm{Cu}$ are all above $55-75 \mathrm{mg} / \mathrm{kg}$, which shows that the vertical distribution is relatively uniform, and there is no obvious trend. In Section 13, the content of $\mathrm{Cu}$ is greater than any other point of content in 0-80 cm depth range; but in Section 6, the content of $\mathrm{Cu}$ is less than any other point of content in 40-100 cm depth range.

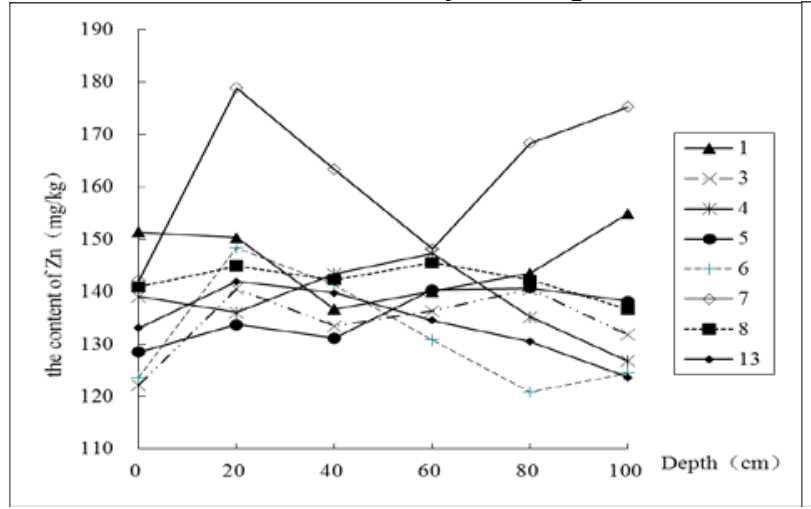

Fig.5

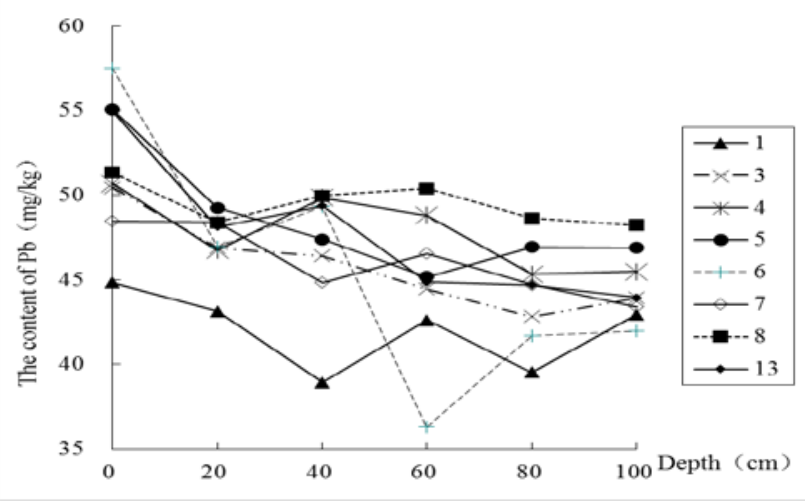

Fig. 6

(5) The vertical distribution characteristics of $\mathrm{Zn}$

From Figure 5, On the overall trend showed declines with the increase of depth, the content of Zn distribution in the range of $120-150 \mathrm{mg} / \mathrm{kg}$ generally. However, section 7 is abnormal and the fluctuation is relatively large, the maximum reached $180 \mathrm{mg} / \mathrm{kg}$, the minimum value reached $140 \mathrm{mg} / \mathrm{kg}$. At the same depth, the content is greater than the other sections. From the geographical position of each section, section 7 is the closest to the tailings reservoir, and it is located in the drainage ditch which is down from the tailings reservoir. So it is possible that the pollutants from the tailings reservoir through the farmland irrigation directly into the point range, the $\mathrm{Zn}$ continues to vertical migration. In the long term, because of the physical and chemical properties of $\mathrm{Zn}$, it has been accumulated, which leads to the pollution degree greater of this point.

(6) The vertical distribution characteristics of $\mathrm{Pb}$

From Figure 6, The content of $\mathrm{Pb}$ was concentrated in the range of $35-60 \mathrm{mg} / \mathrm{kg}$, and the content decreased with the increase of depth. In section 6 , the content of $\mathrm{Pb}$ changed greatly along with the depth, and the value reached the maximum in the surface soil, reached the minimum in the depth of about $60 \mathrm{~cm}$. 


\section{Conclusion}

(1) X-ray fluorescence spectrum method to measure soil heavy metals, the sample doesn't need to digest, can determine a variety of elements simultaneously. After the test, no pollution is produced, the analysis is rapid, and the result is stable and reliable.

(2) In the study area, with the increase of the depth, the content of $\mathrm{Cr}$ increased significantly, and the content of $\mathrm{Pb}$ is decreased, while the content of $\mathrm{Mn}$ in the soil has a slight upward trend in the vertical fluctuation, $\mathrm{Ni}, \mathrm{Cu}$ and $\mathrm{Zn}$ are relatively stable, and the vertical distribution is uniform. $\mathrm{Pb}, \mathrm{Zn}$ and $\mathrm{Mn}$ these three elements is the significant sources of pollution in the tailings which exhibits a maximum value.

(3) The farmland soil around tailings reservoir was polluted more seriously by $\mathrm{Ni}$ and $\mathrm{Cu}$.

\section{Acknowledgments}

This work was supported by the National Natural Science Foundation of China (21407023, 41162007, 41362011).

\section{References}

[1] Hu Ruixia,Gao Bai,Sun Zhanxue,Feng Jiguang: Analysis of the Forms of Heavy Metals in the Soil Down stream of a Uranium Mine's Tailing Dam(Metal Mine, 2009,2:160-162).

[2] YANG Jun,ZHENG Yuanming,CHEN Tongbin: Leaching of heavy metals in soil column under irrigation reclaimed water:a simulation experiment(Geographical Research, 2006, 25(3):449-456).

[3] Yan Xingfeng,Li Gaoping,Wang Jiandang: Heavy metal pollutions of soils and its treatment technology(Studies of Trace Elements and Health,2007, 24 (1): 52-54).

[4] Peng Kunsheng,in: Jiangxi Ecology,volume,3,Jiangxi people's Publishing House(2007)

[5] Yang Guozhi,Wei Fusheng: Basic statistics and characteristics of soil element background values in China (Environmental Monitoring In China,1991,(1):1-6).

[6] Xi Danli, Sun Yusheng, Liu Xiuying,in: Environmental monitoring,Higher Education Press(2010) 